$\xi=1$ -

\title{
Selection of the best supply chain strategy using fuzzy based decision model
}

\author{
Surahman $^{1 *}$, Arkas Viddy $^{1}$, Achmad Fanany Onnilita Gaffar ${ }^{2 *}$, Haviluddin $^{3 *}$, Ansari Saleh Ahmar $^{4}$ \\ ${ }^{1}$ Department of Business Administration, State Polytechnic of Samarinda, East Kalimantan, Indonesia \\ ${ }^{2}$ Department of Information Technology, State Polytechnic of Samarinda, East Kalimantan, Indonesia \\ ${ }^{3}$ Faculty of Computer Science and Information Technology, Mulawarman University, Samarinda, East Kalimantan, Indonesia \\ ${ }^{4}$ Department of Statistic, Universitas Negeri Makassar, Indonesia \\ *Corresponding author E-mail: surahman@ polnes.ac.id, onnygaffar212@gmail.com
}

\begin{abstract}
The right strategy in the supply chain has become strategic issues are important today because the nature of these decisions is usually complex and unstructured. There are many quantitative and qualitative attributes such as cost, responsiveness, and flexibility that need to be taken into account to determine the best supply chain strategy. Assessment of all attributes as mentioned is usually through a human evaluation process involving many subjectivity and uncertainty factors. In addition, the complexity of the problems directly related to each attribute used as an assessment increases the problem of uncertainty. Fuzzy MCDM (Multi Criteria Decision Making) is one of the MCDM methods that use a fuzzy approach to overcome complexity and uncertainty of the problem. Today the market has been able to witness a worldwide expansion and dynamic situation by leveraging new innovations in production methodology and information technology. With this new innovation, the market can increase demand for products tailored to minimum cost with minimum waiting time. Lean and agile are two chain strategy concepts evolved in the pursuit of business excellence, while the concept of leagile is in between. This study aims to select the best supply chain strategy (lean, leagile, agile) at a manufacturing company in Samarinda - East Kalimantan based on certain criteria by using Fuzzy MCDM.
\end{abstract}

Keywords: supply chain strategy; Fuzzy MCDM; strategy selection

\section{Introduction}

Supply Chain Management (SCM) has emerged as a proactive approach to improve business process performance and products according to customer needs. Lead time, cost, quality, level of service, etc., can be considered as the criterion of market winners or criteria of market qualification depending on the type of manufacturing strategy. Supply chain as a series of activities composed by a particular company and all other companies interact directly or indirectly, through its suppliers and customers, upstream and downstream, for the effective consumption of products and/or services by end users. Supply chain management is the strategic and systematic coordination of traditional business functions and tactics across all business functions within specific organizations and across businesses in the supply chain [1]. Supply chain point of view is one of the main opportunities to overcome these barriers and improve performance even for weaker companies [2]. To minimize the overall cost of the system while meeting the customer service level requirements, SCM acts as a series of synchronized decisions and activities that are used to efficiently integrate suppliers, manufacturers, warehouses, transporters, retailers and customers into the right products or services, distributed in the right quantity, to the right location, and at the right time. Lean Manufacturing is the systematic elimination of waste from all aspects of the organization's operations, in which waste is seen as the use or loss of resources that do not lead directly to creating products or services customers expect. Lean manufacturing and JIT (Just In Time) plays an important role in better SCM functionality [3]. Conditions for organization and comfort become more flexible and responsive to customers leads to the concept of agile manufacturing as a discrimination of the lean organization. Agility should be based not only on receptivity and elasticity but also on the cost and quality of goods and services that customers must accept [4]. The explorative case study approach has been used in [5] to identify trade-offs in the context of automotive supply chains that implement Lean, Agile, Resilient and Green (LARG) management paradigms.

The selection of the best supply chain strategy becomes the key to the success of a long-term strategy. As the key to success is how to deliver the right product, at the right time at a reasonable cost to the customer. Based on the characteristics of manufacturing systems there are several types of supply chain strategy as a result of new innovations in production methodology are as follows [6]:

- The production is lean if done with the smallest possible waste due to unnecessary, inadequate, or excessive buffering during the production process.

- The production is agile if it maneuvers efficiently to anticipate uncertainty and varying demands placed upon it.

- Leagile is a manufacturing system that collaborates on various aspects of lean and agile production with efficient coordination of both aspects.

MCDM is a useful tool in many areas such as economics, manufacturing, social, etc. The MCDM addresses the issue of how to select options from a range of alternatives based on certain criteria. This requires information about the preferences of all the criteria used. The decision maker acts as a source of preference for each criterion used as importance weight on the basis of the experience it has [7]. MCDM aims to obtain the most optimal alternative that has the highest level of satisfaction for all relevant 
criteria. The most dominant advantage of MCDM techniques is their ability to analyze quantitative and qualitative criteria. There are many techniques and their combined methods have been proposed to solve MCDM problems [8-15].

Vagueness that exists in many decision-making problems may contribute to the imprecise judgments of decisions made from conventional approaches. Fuzzy theories approach can be used to address the issue of vagueness of human preferential judgment [16]. There are many studies that have been done that combine MCDM methods with fuzzy theory approaches such as in [16-21]. This study aims to select the best supply chain strategy (lean, agile or leagile), according to its characteristics. The fuzzy theory approach is used to overcome complexity and uncertainty issues.

\section{Triangular Fuzzy Number (TFN)}

The linguistic variable (or linguistic value) is a variable whose value is expressed in linguistic terms. The concept of linguistic variables is very useful in dealing with situations that are too complex or not well defined to be expressed in conventional quantitative expression. Mathematical operations are not possible directly on linguistic values. Therefore the linguistic value must be converted to a fuzzy scale by using TFN which is a fuzzy number that represented in three $\tilde{A}=L, M, U$ points as shown in Figure 1 where $L$ is Lower, $M$ is Medium, and $U$ is Upper. Table 1 shows the linguistic value used in this study which expressed by the fuzzy set as shown in Figure 2.

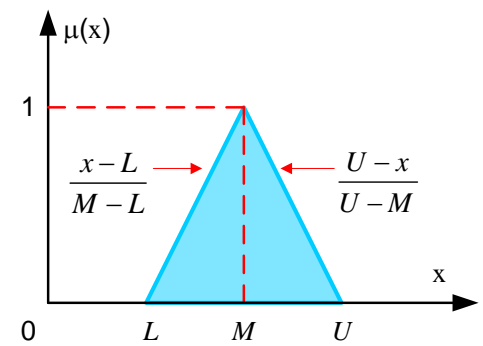

Fig. 1: Triangular Fuzzy Number

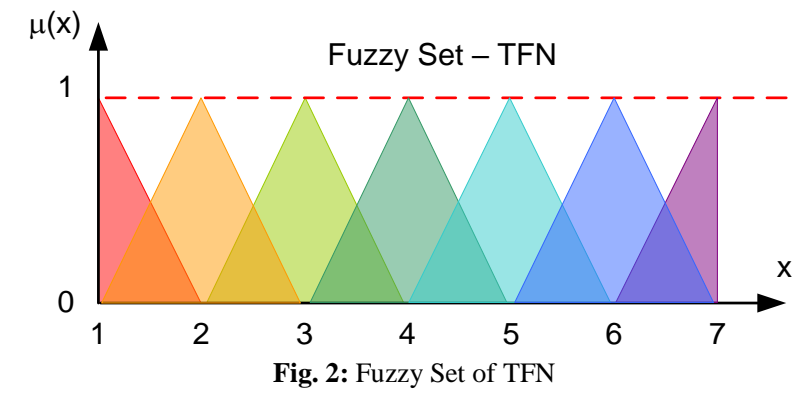

Table 1: Conversion of linguistic value using TFN

\begin{tabular}{|c|c|c|}
\hline $\begin{array}{c}\text { Fuzzy } \\
\text { Number }\end{array}$ & Linguistic value & TFN \\
\hline 1 & $\begin{array}{c}\text { Very Very Low } \\
\text { (VVL) }\end{array}$ & $(1,1,2)$ \\
\hline 2 & Very Low (VL) & $(1,2,3)$ \\
\hline 3 & Low (L) & $(2,3,4)$ \\
\hline 4 & Medium (M) & $(3,4,5)$ \\
\hline 5 & High (H) & $(4,5,6)$ \\
\hline 6 & Very High (VH) & $(5,6,7)$ \\
\hline 7 & $\begin{array}{c}\text { Very Very High } \\
\text { (VVH) }\end{array}$ & $(6,7,7)$ \\
\hline \multicolumn{3}{|c}{} \\
\hline
\end{tabular}

There are some rules for TFN operations [21] as follows:
$\tilde{A}_{1} \oplus \tilde{A}_{2}=L_{1}, M_{1}, U_{1} \oplus L_{2}, M_{2}, U_{2}=L_{1}+L_{2}, M_{1}+M_{2}, U_{1}+U_{2}$

$\tilde{A}_{1} \Theta \tilde{A}_{2}=L_{1}, M_{1}, U_{1} \Theta L_{2}, M_{2}, U_{2}=L_{1}-U_{2}, M_{1}-M_{2}, U_{1}-L_{2}$

$\tilde{A}_{1} \otimes \tilde{A}_{2}=L_{1}, M_{1}, U_{1} \otimes L_{2}, M_{2}, U_{2}=L_{1} \times L_{2}, M_{1} \times M_{2}, U_{1} \times U_{2}$

$\tilde{A}_{1} \varnothing \tilde{A}_{2}=L_{1}, M_{1}, U_{1} \varnothing L_{2}, M_{2}, U_{2}=L_{1} / U_{2}, M_{1} / M_{2}, U_{1} / L_{2}$

Typically, the evaluator consists of several decision makers who provide an assessment based on the linguistic value of Table 1, so it is necessary to aggregate all the results of their assessment, which is expressed by:

$F N_{\text {aggregate }}=\frac{1}{N} \sum_{i=1}^{N} F N_{L}(i)$

$F N_{L}(i)$ is the fuzzy number of $i^{\text {th }}$ linguistic value, and $N$ is the number of the evaluator. For example, if each of the three evaluators gives a rating of $\mathrm{H}$ (high), $\mathrm{M}$ (medium), $\mathrm{M}$ (medium) then the aggregation of the fuzzy number is $(5+4+4) / 3=4.33 \approx 4$. The approximate linguistic value is $\mathrm{M}$ (medium). Eq. (1) is applied to all assessment results provided by all evaluators, for both alternative and criteria assessments.

The fuzzy decision matrix is built from the results of the alternative assessment under the various criteria, and expressed by using TFN as follows:

$D=\left[\begin{array}{cccc}d_{11} & d_{12} & \ldots & d_{1 n} \\ d_{21} & \ldots & \ldots & d_{2 n} \\ \ldots & \ldots & \ldots & \ldots \\ d_{m 1} & d_{m 2} & \ldots & d_{m n}\end{array}\right] \quad d_{i j}=\left[\begin{array}{lll}L_{i j} & M_{i j} & U_{i j}\end{array}\right]$

The fuzzy decision matrix needs to be normalized by dividing it by the total number of $U$ (upper) parts, which expressed by

$\tilde{D}=\left[\begin{array}{cccc}\tilde{d}_{11} & \tilde{d}_{12} & \ldots & \tilde{d}_{1 n} \\ \tilde{d}_{21} & \ldots & \ldots & \tilde{d}_{2 n} \\ \ldots & \ldots & \ldots & \ldots \\ \tilde{d}_{m 1} & \tilde{d}_{m 2} & \ldots & \tilde{d}_{m n}\end{array}\right] \tilde{d}_{i j}=\frac{L_{i j} M_{i j} U_{i j}}{\sum_{i=1}^{N} U_{i j}}$

Decision vectors are expressed by

$\tilde{A}=\tilde{D} \times \tilde{C}=\left[\begin{array}{cccc}\tilde{d}_{11} & \tilde{d}_{12} & \ldots & \tilde{d}_{1 n} \\ \tilde{d}_{21} & \ldots & \ldots & \tilde{d}_{2 n} \\ \ldots & \ldots & \ldots & \ldots \\ \tilde{d}_{m 1} & \tilde{d}_{m 2} & \ldots & \tilde{d}_{m n}\end{array}\right] \times\left[\begin{array}{c}\tilde{c}_{1} \\ \tilde{c}_{2} \\ \ldots \\ \tilde{c}_{n}\end{array}\right]$

Where $\tilde{C}$ is the fuzzy weight of the criteria after being normalized.

Finally, to get the crisp value, it is necessary to do defuzzification by using the centroid method (Center of Area /COA) which expressed:

$x^{*}=\frac{\left(\frac{1}{M-L}\right) \cdot\left[\frac{1}{3} x^{3}-\frac{L}{2} x^{2}\right]_{L}^{M}+\left(\frac{1}{U-M}\right) \cdot\left[\frac{U}{2} x^{2}-\frac{1}{3} x^{3}\right]_{M}^{U}}{\left(\frac{1}{M-L}\right) \cdot\left[\frac{1}{2} x^{2}-L x\right]_{L}^{M}+\left(\frac{1}{U-M}\right) \cdot\left[U x-\frac{1}{2} x^{2}\right]_{M}^{U}}$

Generally, there are several steps to apply the proposed method as shown in Figure 3. 

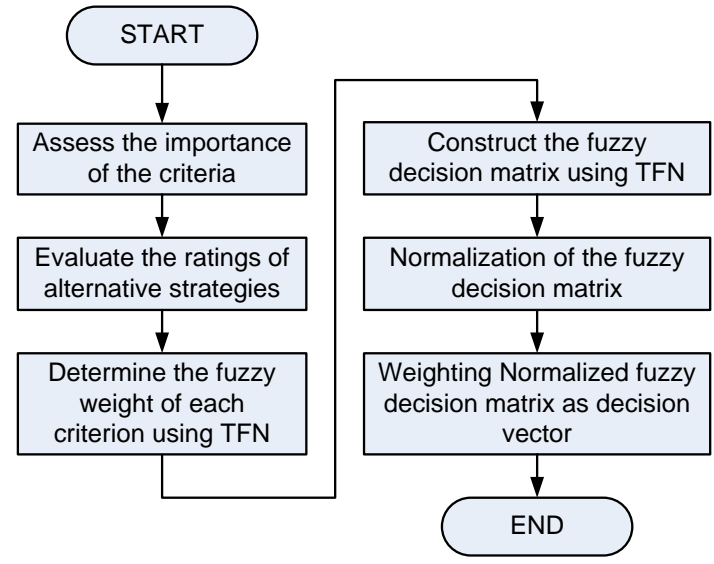

Fig. 3: Fuzzy approach steps

\section{Case Study}

A manufacturing company in Samarinda - East Kalimantan - Indonesia, wants to choose the right strategy to improve the longterm performance of its supply chain. The first step is to build models to identify system alternatives and criteria for evaluating supply chain strategies. The hierarchical model is used to describe complexity in the decision-making process, as shown in Figure 4. This hierarchical model is also used to determine the relative importance of alternative strategies.

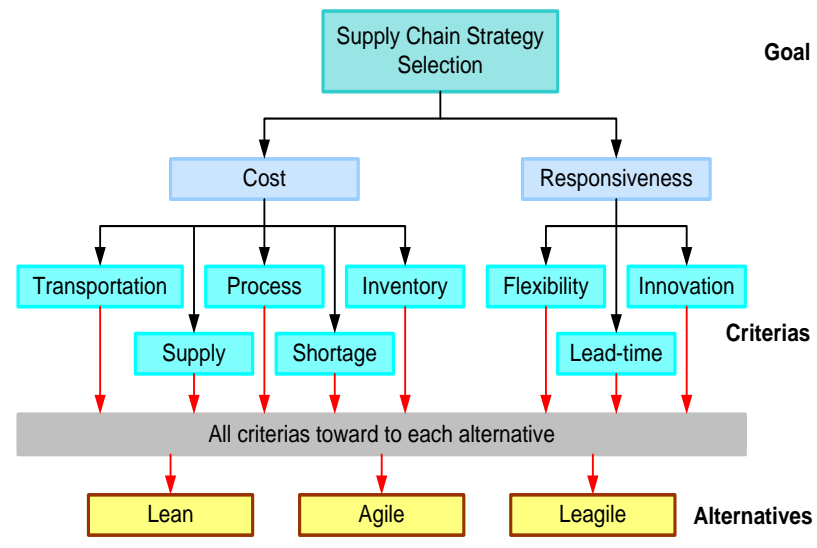

Fig. 4: The hierarchical model

Three decision-makers as evaluators use linguistic scales as shown in Table 1 to assess the importance of criteria. The aggregate importance weights of the criteria determined by these decision makers are calculated using TFN operations as in Eq. (1) which is referred to Table 1. The aggregation results are shown in Table 2. The evaluators use the linguistic value to evaluate the rating of each alternative with respect to its criteria. The aggregate rating of the alternatives under various criteria is shown in Table 3.

Table 2: Aggregated importance weight of criteria

\begin{tabular}{|l|c|c|c|c|}
\hline \multirow{2}{*}{\multicolumn{1}{c|}{ Criteria }} & \multicolumn{3}{|c|}{ Evaluators } & \multirow{2}{*}{ aggregated } \\
\cline { 2 - 4 } & E1 & E2 & E3 & M \\
\hline Cost & H & M & M & M \\
\hline Transportation Cost & VVL & VL & VVL & VVL \\
\hline Supply Cost & H & M & H & H \\
\hline Process Cost & L & M & L & L \\
\hline Shortage Cost & L & L & M & L \\
\hline Inventory Cost & M & H & M & M \\
\hline Responsiveness & H & VH & H & H \\
\hline Supply flexibility & M & M & L & M \\
\hline Total Lead time & H & H & M & H \\
\hline Innovation & VH & H & VH & VH \\
\hline
\end{tabular}

Table 3: Aggregated rating of alternatives under various criteria

\begin{tabular}{|l|c|c|c|}
\hline \multirow{2}{*}{\multicolumn{1}{|c|}{ Criteria }} & \multicolumn{3}{c|}{ Alternatives } \\
\cline { 2 - 4 } & Lean & Agile & Leagile \\
\hline Transportation Cost & H & L & M \\
\hline Supply Cost & H & L & M \\
\hline Process Cost & H & M & H \\
\hline Shortage Cost & M & H & H \\
\hline Inventory Cost & VH & L & M \\
\hline Supply flexibility & VL & VH & M \\
\hline Total Lead time & VL & VH & M \\
\hline Innovation & VL & VVH & M \\
\hline
\end{tabular}

The linguistic evaluations shown in Table 2 were then converted into TFN. The fuzzy weight of each criterion is calculated by using the TFN operation where each TFN criterion is divided by the total TFN. The results of this operation are shown in Table 4. The linguistic evaluations shown in Tables 3 were then converted into TFN to construct the fuzzy decision matrix and the results are shown in Table 5. In the same manner, the results of normalized fuzzy decision matrix are shown in Table 6.

Table 4: The fuzzy weight of aggregated importance weight of criteria

\begin{tabular}{|l|c|c|c|c|c|c|c|}
\hline \multirow{2}{*}{ Criteria } & \multirow{2}{*}{$\begin{array}{c}\text { Linguistic } \\
\text { value }\end{array}$} & \multicolumn{3}{|c|}{ TFN } & \multicolumn{3}{c|}{$\begin{array}{c}\text { Cuzy weight of } \\
\text { criteria }\end{array}$} \\
\cline { 3 - 8 } & L & M & U & L & M & U \\
\hline $\begin{array}{l}\text { Transportation } \\
\text { Cost }\end{array}$ & VVL & 1 & 1 & 2 & 0.026 & 0.032 & 0.083 \\
\hline Supply Cost & H & 4 & 5 & 6 & 0.103 & 0.161 & 0.250 \\
\hline Process Cost & L & 2 & 3 & 4 & 0.051 & 0.097 & 0.167 \\
\hline Shortage Cost & L & 2 & 3 & 4 & 0.051 & 0.097 & 0.167 \\
\hline $\begin{array}{l}\text { Inventory } \\
\text { Cost }\end{array}$ & M & 3 & 4 & 5 & 0.077 & 0.129 & 0.208 \\
\hline $\begin{array}{l}\text { Supply } \\
\text { flexibility }\end{array}$ & M & 3 & 4 & 5 & 0.077 & 0.129 & 0.208 \\
\hline $\begin{array}{l}\text { Total Lead } \\
\text { time }\end{array}$ & H & 4 & 5 & 6 & 0.103 & 0.161 & 0.250 \\
\hline Innovation & VH & 5 & 6 & 7 & 0.128 & 0.194 & 0.292 \\
\hline \multicolumn{1}{|c|}{} & Total & $\mathbf{2 4}$ & $\mathbf{3 1}$ & $\mathbf{3 9}$ & & & \\
\hline
\end{tabular}

Table 5: The fuzzy decision matrix

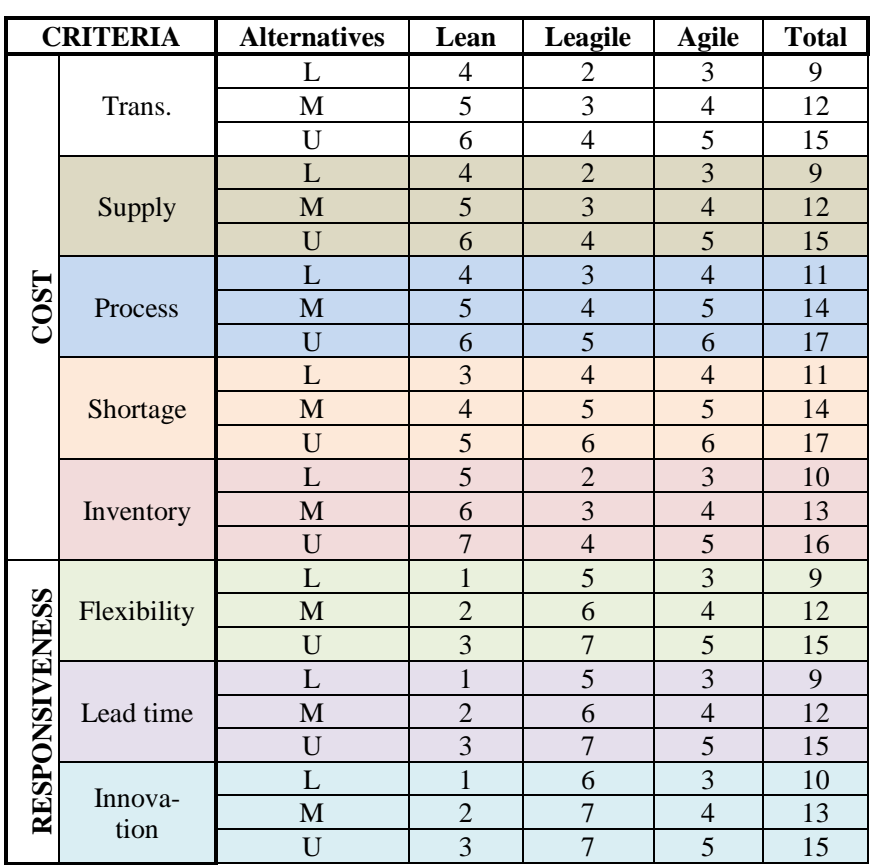


Table 6: The normalized fuzzy decision matrix

\begin{tabular}{|c|c|c|c|c|c|}
\hline \multicolumn{2}{|c|}{ CRITERIA } & Alternatives & Lean & Leagile & Agile \\
\hline \multirow{15}{*}{$\begin{array}{l}5 \\
0 \\
\Xi \\
\end{array}$} & \multirow{3}{*}{ Trans. } & $\mathrm{L}$ & 0.27 & 013 & 0.20 \\
\hline & & $\mathrm{M}$ & 0.42 & 0.25 & 0.33 \\
\hline & & $\mathrm{U}$ & 0.67 & 0.44 & 0.56 \\
\hline & \multirow{3}{*}{ Supply } & $\mathrm{L}$ & 0.27 & 0.13 & 0.20 \\
\hline & & $\mathrm{M}$ & 0.42 & 0.25 & 0.33 \\
\hline & & $\mathrm{U}$ & 0.67 & 0.44 & 0.56 \\
\hline & \multirow{3}{*}{ Process } & $\mathrm{L}$ & 0.24 & 0.18 & 0.24 \\
\hline & & $\mathrm{M}$ & 0.36 & 0.29 & 0.36 \\
\hline & & $\mathrm{U}$ & 0.55 & 0.45 & 0.55 \\
\hline & \multirow{3}{*}{ Shortage } & $\mathrm{L}$ & 0.18 & 0.24 & 0.24 \\
\hline & & $\mathrm{M}$ & 0.29 & 0.36 & 0.36 \\
\hline & & $\mathrm{U}$ & 0.45 & 0.55 & 0.55 \\
\hline & \multirow{3}{*}{ Inventory } & $\mathrm{L}$ & 0.31 & 0.13 & 0.19 \\
\hline & & $\mathrm{M}$ & 0.46 & 0.23 & 0.31 \\
\hline & & $\mathrm{U}$ & 0.70 & 0.40 & 0.50 \\
\hline \multirow{9}{*}{ 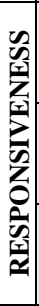 } & \multirow{3}{*}{ Flexibility } & $\mathrm{L}$ & 0.07 & 0.33 & 0.20 \\
\hline & & $M$ & 0.17 & 0.50 & 0.33 \\
\hline & & $\mathrm{U}$ & 0.33 & 0.78 & 0.56 \\
\hline & \multirow{3}{*}{ Lead time } & $\mathrm{L}$ & 0.07 & 0.33 & 0.20 \\
\hline & & $\mathrm{M}$ & 0.17 & 0.50 & 0.33 \\
\hline & & $\mathrm{U}$ & 0.33 & 0.78 & 0.56 \\
\hline & \multirow{3}{*}{ Innovation } & $\mathrm{L}$ & 0.07 & 0.40 & 0.20 \\
\hline & & $\mathrm{M}$ & 0.15 & 0.54 & 0.31 \\
\hline & & $\mathrm{U}$ & 0.30 & 0.70 & 0.50 \\
\hline
\end{tabular}

\section{Results and discussions}

In order to get the crisp value for each mayor criteria, it is necessary to apply Eq. (6). COA of each alternative strategy for each major criteria need to be normalized. The aggregated importance weight of "cost" criteria as shown in Table 2 has a linguistic value "Medium" with the fuzzy number of 4 . It can be expressed in a ratio as 4/7. Using the same approach then the aggregated importance weight of "responsiveness" criteria can be expressed as 5/7. The normalized COA of each major criteria then multiplied by their ratio. The final weight for each alternative is the sum of the weight of all mayor criteria. The results are shown in Table 7.

Table 7: The decision vector

\begin{tabular}{|c|c|c|c|c|c|c|}
\hline \multirow{3}{*}{ Alternatives } & \multicolumn{6}{|c|}{ COST $($ Medium $=4 / 7)$} \\
\hline & \multicolumn{3}{|c|}{ Fuzzy weight } & \multirow{2}{*}{ COA } & \multirow{2}{*}{ Norm } & \multirow{2}{*}{$\begin{array}{l}\text { Weight } \\
x(4 / 7)\end{array}$} \\
\hline & $\mathbf{L}$ & M & $\mathbf{U}$ & & & \\
\hline Lean & 0.079 & 0.202 & 0.535 & 0.272 & 0.387 & 0.221 \\
\hline Agile & 0.048 & 0.140 & 0.398 & 0.195 & 0.278 & 0.159 \\
\hline \multirow[t]{2}{*}{ Leagile } & 0.064 & 0.173 & 0.471 & 0.236 & 0.336 & 0.192 \\
\hline & \multicolumn{3}{|c|}{ Total } & 0.704 & & \\
\hline \multirow{3}{*}{ Alternatives } & \multicolumn{6}{|c|}{ COST $($ Medium $=4 / 7$ ) } \\
\hline & \multicolumn{3}{|c|}{ Fuzzy weight } & \multirow{2}{*}{ COA } & \multirow{2}{*}{ Norm } & \multirow{2}{*}{$\begin{array}{l}\text { Weight } \\
\text { x (5/7) }\end{array}$} \\
\hline & $\mathbf{L}$ & M & $\mathbf{U}$ & & & \\
\hline Lean & 0.021 & 0.078 & 0.240 & 0.113 & 0.180 & 0.129 \\
\hline Agile & 0.111 & 0.249 & 0.561 & 0.307 & 0.490 & 0.350 \\
\hline \multirow[t]{2}{*}{ Leagile } & 0.062 & 0.156 & 0.400 & 0.206 & 0.329 & 0.235 \\
\hline & & & Total & 0.626 & & \\
\hline Alternatives & \multicolumn{6}{|c|}{ Final Weight } \\
\hline Lean & \multicolumn{6}{|c|}{0.350} \\
\hline Agile & \multicolumn{6}{|c|}{0.509} \\
\hline Leagile & \multicolumn{6}{|c|}{0.427} \\
\hline
\end{tabular}

According to COA of its weighted rank, using a linguistic variable to describe the current assessment status of each strategy is a more realistic approach. The five linguistic variables referring to the subinterval are defined to categorize the assessment status into five classes. The decision rules of the five classes are shown in Table 8.

From Table 7 and Table 8, it is known that using presented model, Lean strategy belongs to class 2 , the Agile strategy belongs to class 4 , and Leagile strategy belongs to class 3 . This means that the Agile strategy is the best supply chain strategy with its assessment status is "approved".
Table 8: The approval status

\begin{tabular}{|c|l|l|}
\hline Class & \multicolumn{1}{|c|}{ Final Weight } & \multicolumn{1}{c|}{ Assessment status } \\
\hline 1 & $0-0.2$ & Do not recommend \\
\hline 2 & $0.2-0.35$ & Recommend with high risk \\
\hline 3 & $0.35-0.5$ & Recommend with low risk \\
\hline 4 & $0.5-0.8$ & Approved \\
\hline 5 & $0.8-1.0$ & Approved and preferred \\
\hline
\end{tabular}

\section{Conclusion}

This study has evaluated lean, agile and leagile strategies by using Fuzzy MCDM model to select the best supply chain strategy according to the system characteristics. The hierarchical model has been used to determine the relative importance of alternative strategies to simplify the complexity of the decision-making process in selecting the best supply chain strategy. The systematic stages of strategy selection in a fuzzy environment presented in this study can be easily used to minimize the inappropriate judgments of decision makers caused by vagueness and uncertainty of human preferential judgment.

\section{Acknowledgement}

The authors would like to express their heartfelt thanks to The Modern Computing Research Center, Department of Information Technology, State Polytechnic of Samarinda, for providing all their support.

\section{References}

[1] D. V. Ramana, K. N. Rao, and J. S. Kumar, "A Critical Review on Supply Chain Strategies and their Performance," International Journal of Engineering Science and Computing (IJESC), vol. 6, pp. 4525-4545, (2016)

[2] B. Marchi and S. Zanoni, "Supply Chain Management for Improved Energy Efficiency: Review and Opportunities," Energies, vol. 10, p. 1618, 16 October (2017).

[3] C. D. Singh, R. Singh, J. S. Mand, and S. Singh, "Application of Lean and JIT Principles in Supply Chain Management," International Journal of Management Research and Business Strategy (IJMRBS), vol. 2, (2013)

[4] B. .V. and L. S.N., "An Analysis on Agile Manufacturing System," SSRG International Journal of Industrial Engineering (SSRG-IJIE) vol. 2, pp. 36-40, 3 May (2015).

[5] H. R. Susana Azevedo, Virgilio Cruz-Machado, "Trade-offs among Lean, Agile, Resilient and Green Paradigms in Supply Chain Management: A Case Study Approach," in Proceeding of the Seventh International Conference on Management Science and Engineering Management, (2014), pp. 953-968.

[6] V. P. Rajeev Kant, L. N. Pattanaik, "Lean, Agile \& Leagile Supply Chain: A Comparative Study," ELK Asia Pacific Journals-Special Issue, (2016).

[7] R. K. Gavade, "Multi-Criteria Decision Making: An overview of different selection problems and methods," International Journal of Computer Science and Information Technologies (IJCSIT), vol. 5, pp. 5643-5646, 2014.

[8] A. A. Esfahani, H. Ahmadi, M. Nilashi, M. Alizadeh, A. Bashiri, M. Abbasi Farajzadeh, L. Shahmoradi, H. R. Rasouli, and M. Hekmat, "An evaluation model for the implementation of hospital information system in public hospitals using multicriteria-decision-making (MCDM) approaches," International Journal of Engineering \& Technology (IJET), vol. 7, p. 1, 2017.

[9] L. Fei, Y. Hu, F. Xiao, L. Chen, and Y. Deng, "A Modified TOPSIS Method Based onDNumbers and Its Applications in Human Resources Selection," Mathematical Problems in Engineering, vol. 2016, pp. 1-14, 2016.

[10] F. Ho, S. Abdul-Rashid, and R. Raja Ghazilla, "Analytic Hierarchy Process-Based Analysis to Determine the Barriers to Implementing a Material Efficiency Strategy: Electrical and Electronics' Companies in the Malaysian Context," Sustainability, vol. 8, p. 1035, 2016. 
[11] M. Ibrohim and Sumiati, "Decision Support System for Determining the Scholarship Recipients using Simple Additive Weighting (SAW)," International Journal of Computer Applications (IJCA), vol. 151, pp. 10-13, October, (2016).

[12] N. L. H. T. T. Quyen, P. T. Nguyen, and V. D. B. Huynh, "A hybrid multi criteria decision analysis for engineering project manager evaluation," International Journal of ADVANCED AND APPLIED SCIENCES (IJASE), vol. 4, pp. 49-52, 2017.

[13] P.Venkateswarlu and B. D. Sarma, "Selection of Equipment by Using SAW and Vikor Methods," International Journal of Engineering Research and Application (IJERA), vol. 6, pp. 61-68, (2016).

[14] Purnawansyah and Haviluddin, "K-Means Clustering Implementation in Network Traffic Activities," in 2016 International Conference on Computational Intelligence and Cybernetics, Makassar, Indonesia, 2016, pp. 51-54.

[15] Purnawansyah, Haviluddin, A. F. O. Gafar, and I. Tahyudin, "Comparison between K-Means and Fuzzy C-Means Clustering in Network Traffic Activities," in 2017 International Conference on Management Science and Engineering Management (ICMSEM), 2017

[16] X. Li, Y. Fan, J. W. Shaw, and Y. Qi, "A Fuzzy AHP Approach to Compare Transit System Performance in US Urbanized Areas," Journal of Public Transportation, vol. 20, (2017).
[17] B. Suprapty, R. Malani, and O. D. Nurhayati, "Design of Information System for Acceptance Selection of Prospective Employees Online Using Tahani Fuzzy Logic Method and Simple Additive Weighting (SAW)," International Journal of Computing and Informatics (IJCANDI) vol. 1, pp. 17-28, (2016)

[18] C.-M. Lai, J.-L. Hung, and C.-C. Chen, "A Fuzzy Analytic Network Process for Criteria Evaluation of Sportwear Design and Development," International Journal of Management and Applied Science (IJMAS), vol. 2, pp. 45-49, 2016.

[19] Y. O. Ouma, J. Opudo, and S. Nyambenya, "Comparison of Fuzzy AHP and Fuzzy TOPSIS for Road Pavement Maintenance Prioritization: Methodological Exposition and Case Study," Advances in Civil Engineering, vol. 2015, pp. 1-17, (2015).

[20] P. Sona, T. Johnson, and C. Vijayalakshmi, "Design of a multi criteria decision model-fuzzy analytical hierarchy approach," International Journal of Engineering \& Technology (IJET), vol. 7, pp. 116-120, (2018)

[21] C. Wang, Q. Li, X. Zhou, and T. Yang, "Hesitant Triangular Fuzzy Information Aggregation Operators Based on Bonferroni Means and Their Application to Multiple Attribute Decision Making," The Scientific World Journal, vol. 2014, pp. 1-15, (2014). 